\title{
CUERPO Y NARRAIIVA: UNA A.PROXIMACIÓN EINOGRÁFICA AL PROCESO DE ATENCIÓN DEL EMBARAZO, PARTO Y PUERPERIO DE MUJERES VIVIENDO CON VIH EN LA CIUDAD DE BUENOS AIRES
}

\section{Guadalupe García}

\section{Universidad de Buenos Aires - Argentina}

Resumen: Este trabajo es parte de una investigación más amplia, uno de cuyos objetivos es indagar el modo en que la experiencia en la atención médica y la utilización de procedimientos para evitar la trasmisión perinatal del VIH reconfiguran la experiencia de vivir con la enfermedad y los sentidos asignados a la maternidad y al VIH-SIDA por parte de las mujeres afectadas. En este artículo exploro el papel que el saber médico y las condiciones de la atención obstétrica juegan en la producción de sentidos y significaciones sobre el cuerpo en mujeres infectadas por el VIH. Al considerar el carácter específico del cuerpo -objeto y sujeto-, el abordaje etnográfico y el análisis de narrativas posibilitan traspasar los límites de un enfoque exclusivamente representacional. Así, analizo los relatos de cuatro mujeres infectadas por el VIH, recopiladas en el marco de una etnografía hospitalaria en un centro obstétrico del sur de la ciudad de Buenos Aires.

Palabras clave: cuerpo, etnografía hospitalaria, narrativa, trasmisión madre-hijo del VIH.

Abstract: This paper is part of a wider research aimed to study the way in which medical care and the use of procedures to prevent HIV perinatal transmission shapes the experience of living with this sickness and the meanings given to motherhood and HIV by women suffering from this condition. I explore the role played by medical knowledge and the conditions of medical attention in the production of meanings about the body in HIV infected women. Considering the specificity of human body - both subject and object-, the ethnographic approach and narrative analysis allow us to go beyond the limits of an exclusively representational point of view. Thus, I analyze the accounts of four women living with HIV framed in a hospital ethnography in a obstetrical centre in southern Buenos Aires city.

Keywords: body, hospital ethnography, mother to child HIV trasmission, narrative. 
Es difícil seguir siendo emperador ante un médico, y también es difícil guardar la calidad de hombre. El ojo de Hermógenes sólo veía en mí un saco de humores, una triste amalgama de linfa y sangre.

Margarite Yourcenar, Memorias de Adriano

En las últimas décadas, el "problema del cuerpo" en la atención biomédica ha sido abordado desde diferentes perspectivas y abordajes en la sociología y antropología médicas y ha constituido un fértil campo de debates y discusiones disciplinares. El propósito de este trabajo es revisitar algunos de los nudos conceptuales que emergen de esta abundante literatura a fin de abordar algunos interrogantes y ejes de análisis que son parte de una investigación más amplia en curso.

De modo general, el trasfondo sobre el cual se despliega este artículo -como una suerte de metaobjetivo- es la búsqueda y el desarrollo de una perspectiva etnográfica y relacional del proceso de atención del embarazo, parto y puerperio en mujeres que viven con VIH. Eduardo Menéndez (2008) ha planteado la necesidad del desarrollo de una perspectiva analítica que permita dar cuenta de las articulaciones, transacciones o negociaciones y evite plantear los problemas en términos de polaridades en oposición. De alguna manera, en este trabajo pretendo asumir este reto emprendiendo la búsqueda de un abordaje etnográfico que posibilite dar cuenta de la compleja gama de procesos y relaciones que modelan y configuran el proceso de atención médica de las mujeres afectadas. Con ello no procuro encontrar una respuesta definitiva a tales cuestiones, sino dar un horizonte a mis reflexiones.

Desde la notificación del primer caso femenino de Sida en Argentina en 1987, la razón hombre-mujer, que comenzó siendo de 92/1, mostró una tendencia descendente sostenida, siendo en el período 2001-2002 1,9/1 y 1,7/1 en los períodos 2003-2004 y 2005-2006. Según estudios epidemiológicos, en Argentina la epidemia afectó en un comienzo a varones de entre 30 y 39 años, mientras que desde mediados de los '90 se comenzó a informar un lento y sostenido crecimiento de casos entre mujeres principalmente en 
edad reproductiva. Así, entre el año 2001 y el 2007 se notificaron 34803 personas infectadas por el VIH, de las cuales 12787 fueron mujeres, siendo el grupo etario 20-34 años el más afectado. En cuanto a la vía de trasmisión, el $81,6 \%$ de los casos femeninos fue notificado como relaciones heterosexuales sin protección.

El incremento de la epidemia entre las mujeres ha impactado en una mayor preocupación de los organismos oficiales por el problema de la trasmisión vertical o madre-hijo del VIH. Ésta fue la vía de trasmisión informada para el 94\% de los 1572 casos de infección por VIH notificados en menores de 14 años hasta el año 2007. Se estima que 788 de ellos nacieron en el período 2001-2007 (Ministerio de Salud, 2008).

La atención médica del embarazo de las mujeres infectadas por el VIH tiene actualmente como su objetivo central el evitar la trasmisión perinatal del virus $^{1}$ y un enorme caudal de los recursos disponibles en el área se destinan a financiar proyectos diversos de prevención en este tema. En este marco, se han conformado numerosos equipos "interdisciplinarios" en varios centros de atención de la ciudad de Buenos Aires y en algunos menos del conurbano bonaerense ${ }^{3}$ y otros centros urbanos del país para abordar esta problemática que es un punto fundamental de los planes estratégicos de organismos gubernamentales municipales, provinciales y nacionales. "Que ningún niño nazca

1 Básicamente los procedimientos para prevenir la trasmisión vertical están organizados en tres componentes:

1) durante el embarazo: prescripción de tratamiento antirretroviral a partir de la semana 14 de gestación;

2) durante el parto: goteo de AZT y -si la mujer tiene el estudio de carga viral (cantidad de virus por unidad de medida de sangre) con un valor superior a 1000 copias- realización de una cesárea programada; si el valor del estudio es inferior a las 1000 copias se recomienda el parto por vía vaginal a fin de reducir el riesgo de infección quirúrgica o postquirúrgica;

3) al recién nacido: tratamiento de profilaxis con Bactrim y jarabe AZT los primeros meses de vida.

A partir de la disponibilidad de estos procedimientos se estableció como obligatorio (ley 25543) el ofrecimiento del test para VIH como parte de los controles prenatales de rutina.

2 Pongo interdisciplinarios entre comillas porque muchas veces estos equipos se presentan institucionalmente de ese modo pero están compuestos únicamente por profesionales médicos de distintas especialidades (obstetra, infectólogos, etc.). Aun así, frecuentemente, cuando estos equipos están integrados por profesionales de distintas áreas, el funcionamiento y la integración de las distintas perspectivas resulta problemático (ver Gagliolo, 2006).

3 El denominado conurbano bonaerense está compuesto por 19 partidos de la provincia de Buenos Aires que conforman el área que rodea a la ciudad autónoma de Buenos Aires. Conjuntamente con ésta se denominan Área Metropolitana de Buenos Aires.

Horizontes Antropológicos, Porto Alegre, ano 15, n. 32, p. 247-272, jul./dez. 2009 
con VIH" es un manifiesto obligado en los discursos de ministros y personalidades en el día nacional de lucha contra el Sida. ${ }^{4}$

Así, la agenda pública sobre VIH-Sida tiene como una de sus prioridades la reducción de los índices de trasmisión vertical. Este punto, sin duda de primera importancia en las políticas y prácticas relacionadas con el tema, se organiza, sin embargo, sobre la base de un tipo de abordaje que recorta sus acciones a la prevención de la trasmisión perinatal omitiendo una respuesta integral al conjunto de requerimientos de las mujeres que se embarazan y tienen hijos estando afectadas por esta enfermedad estigmatizada y frecuentemente asociada con la muerte. Debe subrayarse además que un $41,4 \%$ de las mujeres infectadas que tuvieron sus partos en alguna maternidad pública de la ciudad de Buenos Aires fueron diagnosticadas durante el embarazo, el trabajo de parto, el puerperio o durante algún embarazo anterior (3,6\%) (Coordinación Sida, 2006).

El objetivo de este trabajo es aproximarnos a la experiencia de estas mujeres centrándonos en el proceso de atención del embarazo y parto y focalizando en el papel que el saber médico y la experiencia en la atención obstétrica juegan en los modos en que ellas viven y significan sus cuerpos. Para ello presentaremos las narrativas sobre la atención obstétrica de cuatro mujeres viviendo con VIH que conocimos durante la realización de una etnografía hospitalaria.

Entendemos que la enfermedad implica un quiebre en la vida cotidiana y la biografía de las personas afectadas, cuestionando la "actitud natural" con la que se desenvuelven y viven en el mundo y exigiendo la construcción de un nuevo orden de cosas, una nueva cotidianeidad significativa (Alves; Rabelo; Souza, 1999). En ese proceso de (re)construcción y (re)organización, el cuerpo se sitúa en primer plano y deviene en un objeto específico y privilegiado de atención (Kirmayer, 1992), interrumpiendo la "presencia-ausente" que lo caracteriza en la vida cotidiana ordinaria (Williams, 1996). Tal como ha señalado Merleau-Ponty, la enfermedad sujeta al hombre a los ritmos vitales de su cuerpo, violenta los ritmos normales de la vida, "[...] invadiendo la

\footnotetext{
4 Cabe destacar que a pesar de toda esta movilización de recursos financieros y humanos, según los datos del último boletín del Programa Nacional de Lucha contra los Retrovirus del Humano, VIH-Sida y ETS del Ministerio de Salud y Medio Ambiente de la Nación (agosto 2008) que presentamos más arriba en el texto continúan presentándose infecciones por esta vía aun en años recientes. No se han publicado oficialmente datos actuales sobre la tasa de trasmisión a nivel nacional.
} 
experiencia cotidiana con su presencia distorsionante, y focalizando nuestras preocupaciones sobre el cuerpo como un objeto, alienando la experiencia del Yo [...]" (Merleau-Ponty, 1993 apud Recoder, 2006, p. 62). Así, la enfermedad no sólo pone en cuestión nuestro vivir cotidiano, sino que también interrumpe el transcurrir silencioso del cuerpo en la vida ordinaria y, como ha señalado Beatriz Cortés (1997), tensiona la integridad de la imagen que el sujeto tiene de sí. Pero, mientras las personas experimentan la enfermedad en el contexto de sus "cuerpos vividos", la intervención médica lo construye como su objeto en términos de un cuerpo atomizado, medicalizado, ahistórico y desocializado (Good, 1994; Good; Del Vecchio Good, 2000).

Es por ello que el cuerpo constituye un nudo problemático central en nuestra búsqueda teórico-metodológica, ya que, merced a su doble carácter de sujeto y objeto, puede conferirnos una perspectiva privilegiada para explorar perspectivas relacionales del proceso de atención médica.

En un trabajo anterior (García, 2007a) estudiamos las modalidades de atención médica y la gestión y administración de programas y normativas de prevención de la trasmisión perinatal del VIH-Sida en un hospital público de la ciudad de Buenos Aires. Al analizar lo que denominamos "la construcción de la paciente" abordamos el modo en que la intervención médico-obstétrica formulaba su objeto, organizando la realidad en términos médicos (Good, 1994). Así, sostuvimos que en el proceso de atención médica del embarazo, éste, entendido como proceso biológico, constituía el centro excluyente de atención y cuidados. En este marco, la atención de las mujeres infectadas embarazadas se organizaba en un circuito en el cual el trabajo entre los distintos profesionales se efectuaba a partir de la división de competencias sobre las cuales intervenir (entendidas como distintos desórdenes fisiológicos estructurales y funcionales): los médicos obstetras monitoreaban el desarrollo del embarazo, mientras que los médicos infectólogos controlaban los indicadores de la progresión del virus y la carga viral mediante la prescripción del tratamiento antirretroviral.

Beatriz Cortés (1997, p. 89) ha analizado el modo en que el sistema de atención y la relación médico-paciente pueden conducir a profundizar "la fragmentación que una persona experimenta consigo misma a partir de su padecimiento" y designa como "el malentendido de la cura" al frecuente desencuentro en la relación médico-paciente. En los términos de la autora, la enfermedad implica un proceso de ruptura en el transcurrir silencioso del cuerpo y la demanda de atención es parte de la búsqueda de "reorganización 
e integración del sujeto con su cuerpo a través del vínculo con el médico" (Cortés, 1997, p. 89). Así, la búsqueda de atención médica implica una doble demanda: de curación de la enfermedad y de resignificación del padecimiento. Pero esta demanda está dirigida a un profesional cuyo modo habitual de intervenir es a partir de la disociación de la enfermedad y el sujeto, agudizando la separación de éste con respecto a su cuerpo.

Nuestra pregunta es, entonces, ¿cómo se expresa este "malentendido" en la manera en que las mujeres afectadas viven y significan su cuerpo?, ¿cómo es vivida la fragmentación del cuerpo que supone vivir, atenderse y embarazarse estando infectada por el VIH?, y, fundamentalmente, ¿de qué modo es posible una (re)integración?

II

Estos interrogantes nos sitúan frente a la cuestión de cómo abordar el problema del cuerpo. Problema que se plantea en la medida en que reconocemos que el cuerpo no es sólo un objeto en el mundo de los objetos sino que constituye el fundamento y la base misma de la experiencia, esto es, es el vehículo para pensar, sentir y actuar (Kirmayer, 1992). El cuerpo, entonces, no es sólo la imagen corporal que puede ser analizada por una teoría exclusivamente representacional y el desafío que se nos presenta es justamente restituir en nuestro análisis este doble carácter.

El análisis de narrativas en el marco de un abordaje etnográfico nos permite aproximarnos al nexo fundamental entre narración y contexto vivido. El íntimo vínculo entre la actividad de narrar y la existencia humana se efectúa, según Ricoeur (1995), a partir de la correlación de la configuración temporal de una y otra. Así, la estructura comienzo-desarrollo-fin, característica de la narrativa, es una parte integrante de la acción y de las experiencias cotidianas de los sujetos (Alves; Rabelo; Souza, 1999).

Partimos del supuesto de que las narrativas son una vía de acceso a la experiencia, ya que a través de los relatos sobre eventos vividos las personas representan, comunican y (re)cuentan esa experiencia. Esto no implica reducir la vida a la dimensión del discurso, ya que la experiencia excede siempre las posibilidades de su descripción o narrativización (Good, 1994), sino que requiere reconocer que el narrar, el "contar una historia" sobre eventos vividos, 
es una dimensión fundamental de la vida misma de los sujetos y constituye el significado de la experiencia.

Como ha señalado Ricoeur (1995), la configuración de la trama narrativa posibilita que la experiencia, siempre fragmentaria, cobre sentido como una totalidad. La construcción de una trama implica el ordenamiento y la transformación de una serie de eventos que de otro modo permanecerían inconexos proporcionando una explicación de los mismos desde una perspectiva particular ubicada en el presente. Pero son también nuestras preocupaciones y proyecciones sobre el futuro las que organizan y modelan nuestra reconstrucción narrativa del pasado (Garro; Mattingly, 2000). Así, a través de las narrativas personales los sujetos evalúan las acciones, el curso y el valor de la vida, y se elaboran, enmarcan e interpretan eventos y concepciones del pasado, articulándolos con el presente y con la elaboración de un futuro posible (Barber; Margulies, en prensa). Desde esta perspectiva, no hay eventos pasados y externos que aguardan ser narrados, sino que los sucesos y su interconexión se construyen y proyectan en el curso mismo de la actividad narrativa.

Recuperamos también el vínculo entre el relato y el contexto de interlocución (Rabelo, 1999) y desde este punto de vista analizamos las narrativas como relatos abiertos, construidos en el curso de la experiencia de vivir, embarazarse y atenderse por VIH y como búsquedas de articulación de los eventos, las vivencias, los síntomas y las consecuencias sociales de vivir con VIH-Sida y su integración en la vida cotidiana. Los relatos, así, son producciones personales y sociales situadas en un cierto momento de las trayectorias de la vida con la enfermedad y en un cierto contexto de desarrollo de la biomedicina (Barber; Margulies, en prensa).

Los relatos y las trayectorias que analizamos en este trabajo fueron recopilados en el marco de una etnografía hospitalaria en un centro obstétrico de un hospital público de agudos del sur de la ciudad de Buenos Aires. ${ }^{5,6}$ Esto

\footnotetext{
Cabe destacar que este centro de atención ocupa el segundo lugar -tras un hospital materno-infantil- en las estadísticas municipales sobre el número de partos anuales y recibe, además, la demanda de atención de mujeres residentes de la ciudad y de un amplio radio de partidos del suroeste bonaerense.

6 Este estudio constituye un línea individual dentro de una investigación etnográfica más amplia realizada en conjunto con la Lic. Nélida Barber y la Prof. Gisela Galgiolo en el marco del proyecto "Crecer, Vivir y Atenderse por VIH-Sida. Un estudio antropológico de las experiencias de vida cotidiana y tratamiento médico en la ciudad de Buenos Aires y conurbano bonaerense" (UBACyT F095 programación 20042008) dirigido por la Dra. Susana Margulies.
}

Horizontes Antropológicos, Porto Alegre, ano 15, n. 32, p. 247-272, jul./dez. 2009 
supuso la permanencia, observación y circulación en distintos espacios de atención y la interacción continuada con las distintas personas involucradas. ${ }^{7}$ Entendemos que el abordaje etnográfico posibilitó una mirada integral del proceso de atención del embarazo, parto y puerperio de las mujeres afectadas, así como analizar y situar a las narrativas sobre la atención médica en los contextos interaccionales de la institución hospitalaria.

Finalmente, conocimos a las mujeres en el marco de la atención médica, por lo tanto las narraciones metodológicamente son relatos producidos en el contexto del hospital y de la interacción entre entrevistado y entrevistador, lo cual influye en la forma, presentación e interpretación de los mismos. ${ }^{8}$

III

Olivia tenía 26 años cuando se fue de vacaciones a Misiones, una provincia del nordeste de Argentina, donde vive su hermana y conoció a un "misionero". Semanas después, ya en Buenos Aires, se dio cuenta que tenía un "retraso" y descubrió que estaba embarazada. Enseguida llamó a su compañero del verano y le contó que iba a ser padre, él negó su paternidad y le dijo que no tenía nada que ver con su embarazo. Ella lo escuchó y no volvió a hablar más con él, de todos modos estaba contenta "porque, ponele, cuando una mujer llega a tal edad como que ya quiere ser madre una cosa así, y tenía ponele 26 , 27 y como que veía que me pasaba el tiempo". A los tres meses acudió al hospital para hacerse los controles y entre los análisis le realizaron un test de Elisa para VIH. Este último hecho sólo cobró notoriedad posteriormente ya que no

\footnotetext{
Así, realicé observaciones en la sala de espera del centro obstétrico y del servicio de infectología, en los pasillos internos de la maternidad, en consultas obstétricas de primera vez, en consultas gineco-obstétricas de guardia -urgencias-, en los pabellones de internación, en la sala de ecografías y monitoreo fetal, en los salones de la sala de trabajo de parto, parto y posparto, en el "office" del personal médico de guardia, en el hospital de día pediátrico y en el sector de neonatología. Además de las interacciones y conversaciones informales con mujeres, familiares y personal de salud, realicé entrevistas en profundidad con pacientes, médicos/as infectólogos, médicos obstetras, residentes de tocoginecología, parteras de planta y residentes, médicos neonatólogos, infectóloga pediatra, jefes de servicio, trabajadoras sociales, jefa de laboratorio, jefa de farmacia y funcionarios de la Coordinación Sida de la ciudad de Buenos Aires.

8 En este sentido sostenemos que la audiencia juega un rol activo - de coautoría- en la producción narrativa (Ochs; Capps, 1996). Contar una historia, escuchar una historia, es un acto relacional y un proceso constructivo situado en y constituido por un escenario interaccional particular pero también cultural, social e histórico (Garro; Mattingly, 2000).
}

Horizontes Antropológicos, Porto Alegre, ano 15, n. 32, p. 247-272, jul./dez. 2009 
recuerda si sabía que le estaban ordenando la prueba. Cuando le pregunté si le habían avisado ${ }^{9}$ o explicado por qué le pedían el test se sorprendió y hasta casi se ofendió "supuestamente a todas las embarazadas le hacen el HIV". Olivia se quedó pensando en la pregunta y en varios encuentros posteriores hablamos sobre el tema: "yo en realidad creo que todo el mundo sabe que cuando estás embarazada te lo hacen y sé que por ahí en los trabajos te tienen que avisar o tenés que firmar algo, en los trabajos sí, pero yo supongo que... no me parece mal que no te digan cuando estás embarazada, después no sé". Una semana después de la primera consulta recibió un sobre que le solicitaba presentarse el lunes siguiente en consultorios externos de obstetricia. Acudió con su mamá una semana después y allí le comunicaron que el test Elisa había resultado reactivo: "y bueno ahí empecé a llorar no sabés cómo, no paraba, no paraba, no paraba". En la narración de Olivia, la vivencia del embarazo aparece signada por el diagnóstico comunicado recientemente:

[...] cuando me enteré [del embarazo] sí, estaba [contenta] lo que pasa que es difícil porque... ponele alguien que no tiene nada está re-contento, no sé qué, yo por un lado estaba contenta pero por el otro ¿entendés? estaba re-mal por eso, como que no pude disfrutar del embarazo, como que por ahí me tapaba más lo otro y, y bueno, a veces como que me acuerdo y... [con voz llorosa] y me da como cosa, pero bueno ya está [llora] [...]. (Olivia).

Vanina tenía 22 años cuando se casó. Al poco tiempo tuvo una hija. Trabajaba en una carnicería que tenía su suegro dentro de un supermercado. Un buen día el suegro, "un jugador compulsivo" como ella lo define, desapareció con "toda la plata” y nunca más volvió. Ella le pidió al dueño del supermercado hacerse cargo sola de la carnicería, trabajo que debía conciliar con el cuidado de su hija: "a mí siempre me gustó trabajar, no era de quedarme en mi casa, yo me iba con la nena a las siete de la mañana, la llevaba, la tenía todo el día en el negocio, venía siempre con la nena a cuesta”. Al poco

\footnotetext{
9 Según la ley nacional de Sida (23798) de 1990 y numerosas recomendaciones y normativas de la Coordinación Sida del Gobierno de la Ciudad de Buenos Aires, para solicitar un test de Elisa para VIH la persona debe consentir el estudio - esto es, se trata de una prueba voluntaria y no obligatoria-, tras haber sido asesorada por el personal de salud sobre los motivos por los cuales se solicita la medida diagnóstica y las características de la prueba.
}

Horizontes Antropológicos, Porto Alegre, ano 15, n. 32, p. 247-272, jul./dez. 2009 
tiempo contrató una persona para que la ayudara: "ahí empezó todo". Tuvo una "aventura" con él y dejó a su marido. "después de un tiempo decidí no cuidarme, termino quedando embarazada", el embarazo no había sido buscado y su primer impulso fue abortar, pero finalmente decidió tenerlo y hacerse los controles. Empezó con los estudios en una clínica privada porque la persona con quien había tenido "la aventura" se iba a "hacer cargo de la criatura" y "afrontar los gastos". Allí le pidieron el test de Elisa para VIH. Tampoco recuerda haber firmado un consentimiento, simplemente "estaba incluido" dentro de los estudios de rutina que le practican a toda embarazada y ella ya lo sabía por su embarazo anterior. A los pocos días el médico de la clínica la llamó a su casa diciéndole que algunos resultados "habían salido mal" y que debía verlo de manera urgente. Al día siguiente concurrió a la clínica y le comunicaron que el test había sido reactivo y que debía realizarse las pruebas confirmatorias: "bueno mi primera reacción que... cuando me lo dijeron no lo podía creer, no estaba en mis planes y... o sea lo primero que pensé es en morir, tenés... decirme que tenía sida era que te estabas por morir”. A partir de entonces dejó de atenderse en la clínica privada y comenzó a concurrir al centro obstétrico donde nos conocimos, ingreso que efectuó por la guardia a los pocos días de recibir el primer resultado.

[...] cuando me enteré ese fin de semana, estuve llorando todo el fin de semana, mi marido se había llevado a mi nena, estuve todo el domingo, un domingo muy... con fiebre y al otro día me levanté y me vine para acá, me vine a la guardia [...]. (Vanina).

Tanto Olivia como Vanina, del mismo modo que las otras mujeres que conocimos, fueron diagnosticadas durante el embarazo sin recibir asesoramiento sobre la realización de la prueba diagnóstica; tampoco recibieron posteriormente información sobre las implicancias del diagnóstico para su propia salud y su futuro. En el contexto de un sistema de atención dirigido a la prevención de la trasmisión madre-hijo, el único asesoramiento que estas mujeres manifestaron haber recibido cuando se les comunicó su seropositividad fue el referido al "adecuado" cumplimiento del tratamiento de profilaxis. Aun cuando la mayor parte de las mujeres comparte la relevancia otorgada a este objetivo, su cumplimiento en la atención médica no parece incluir la consideración de sus propios temores, deseos, necesidades y requerimientos. 
El recibir un diagnóstico de infección por VIH durante el embarazo fue para todas mujeres, una experiencia que abrió para ellas un futuro incierto y las interpeló sobre el pasado y sobre sí mismas. El diagnóstico no sólo las enfrentó con los imaginarios sociales sobre los afectados por el virus (Grimberg, 2003) sino que también las confrontó con sus propias historias y relaciones.

En este proceso, el cuerpo adquiere una nueva visibilidad a través de la propia vulnerabilidad, deviniendo así en un objeto específico y privilegiado de atención (Kirmayer, 1992). Al mismo tiempo se torna, para la intervención médica pero también para las mismas mujeres, en una suerte de medio -escindido, separado de sus propias historias y sentimientos- que, como futuras madres, deben disponer para los estudios y prácticas terapéuticas destinadas a proteger al hijo/a que esperan. Si la enfermedad pone en cuestión la integridad de la imagen que los sujetos tienen de sí, en el caso de estas mujeres, esta fragmentación se ve reforzada al tener que dirigir sus cuidados y gran parte de su energía para evitar la trasmisión al hijo que esperan. Así, la medicación se toma para que el bebé no se infecte y no por la propia situación inmunológica, ${ }^{10}$ los controles de CD4 y carga viral se realizan para definir la vía de parto que implique menores probabilidades de trasmisión.

Pero al mismo tiempo tanto el relato de Olivia como el de Vanina ponen de manifiesto que en el proceso de recibir un diagnóstico de infección por VIH y empezar a reconocerse como afectadas, el dolor, la angustia y el miedo no sólo son racionalizados sino que son vividos y sentidos en y por los cuerpos. Así lo expresa el llanto de Olivia, no sólo el que es contado, sino también el del momento mismo en que narra cómo vivió el embarazo, cómo le comunicaron el diagnóstico y cómo ella lo contó a otros, y en el caso de Vanina, nuevamente el llanto (el relatado y el vivido durante la entrevista) y también la fiebre.

\footnotetext{
${ }^{10}$ A este respecto debe subrayarse que no se conocen aún los efectos a largo plazo que las drogas que se prescriben a mujeres embarazadas pueden tener sobre los niños, ni tampoco se ha establecido con claridad los efectos que la prescripción de medicación antirretroviral durante el embarazo puede tener en el posterior tratamiento de la mujer, ya que tanto el uso temprano de medicación como el empleo irregular de la misma (con esto nos referimos a la suspensión del tratamiento luego del embarazo) puede favorecer la aparición de resistencias del VIH a las drogas.
} 
IV

El diagnóstico y la confirmación de la infección por VIH abrieron, para estas mujeres, un nuevo circuito de atención dentro del hospital. En este sentido, tanto Olivia como Vanina, en sus entrevistas marcaron un contraste entre ellas y "las embarazadas normales". En ambos casos el nuevo circuito se inauguró con la primera visita a la infectóloga en el momento inmediatamente posterior al diagnóstico y conducidas por la persona que se los comunicó. A partir de entonces las mujeres debieron ir al hospital para realizar consultas obstétricas y también consultas infectológicas, estudios de laboratorio, estudios de carga viral y CD4, trámites para retirar gratuitamente la medicación en el Ministerio de Salud (sólo la primera vez), retirar la medicación en la farmacia del hospital, ecografías. Estas prácticas se inscriben en un circuito de atención fragmentado y desarticulado y son las mujeres las que, a través de sus trayectorias y de sus estrategias dentro del hospital, articulan estas distintas instancias de atención entre sí (García, 2007b; Menéndez, 1990).

En lo que respecta a la determinación de la vía de parto, tanto los médicos obstetras como los infectólogos señalaron que ésta se efectúa a partir de la evaluación de "factores infectológicos" en función del resultado obtenido en el estudio de carga viral ${ }^{11}$ efectuado en el último trimestre del embarazo:

[...] en general paciente que tenga más de mil copias es la indicación de la cesárea $[\ldots]$... (Médica infectóloga).

En estos casos la indicación de una cesárea es indiscutible. Sin embargo, un valor menor a las 1000 copias no se corresponde necesariamente con la realización de un parto por vía vaginal:

[...] si yo tengo una paciente que tiene menos de mil copias en general es lo mismo que vaya a cesárea en cuanto a riesgo de transmisión que a parto [...] (Médica infectóloga).

11 La carga viral es la cantidad de copias del VIH por unidad de volumen de sangre y se considera un indicador fundamental del avance de la infección. 
[...] la única causa por la cual puede ir a un parto (por vía vaginal) es cuando un examen complementario, un análisis que se le hace que se llama carga viral que cuenta la cantidad de virus que hay en sangre, es menor a mil, es lo mismo que tenga parto o cesárea [...] en ese caso no es que aumente la posibilidad por haber tenido un parto [...] porque es casi insignificante la cantidad de virus en sangre, que hace que sea lo mismo tener un parto que tener una cesárea [...] a menos que tenga alguna causa obstétrica que tengamos que hacer una cesárea [...]. (Médico obstetra de "alto riesgo").

Interviene, entonces, la evaluación variable de los denominados "factores obstétricos" que pueden incluir las características del desarrollo de la gestación y/o los antecedentes de la mujer - por ejemplo, cesáreas previas. Así, en la definición de la vía del parto se combinan criterios de decisión provenientes de las distintas áreas de especialización que abordan los cuerpos de estas mujeres y la única indicación clara es la de la cesárea. Fundamentalmente estos consisten, además, en esquemas estrictamente biomédicos, ajenos a la inclusión o consideración del deseo, las expectativas y la experiencia de las mujeres. ${ }^{12,13}$

Paula nació en Paraguay, a unos kilómetros de la capital Asunción hace 20 años. Allí vivía con su pareja, cerca de su mamá y su familia. Hace tres años decidió venir sola a Buenos Aires y buscó a su papá a quien no conocía. Desde entonces vive con él en un barrio de emergencia de la ciudad donde tienen, según ella describe, una "pequeñísima” panadería. En sus primeros tiempos acá en Buenos Aires trataba de viajar para visitar a su familia y ver a su expareja, fue así como ella dice que quedó embarazada. Empezó a controlarse

12 A este respecto, cabe señalar que ningún profesional hizo referencia, ni en las entrevistas, ni en conversaciones informales llevadas a cabo durante el trabajo de campo, a los deseos o pedidos de las mujeres en relación con la vía de parto. Tampoco refirieron alguna instancia o momento durante la atención en que se le consultara sobre sus expectativas.

13 Posteriormente al parto, durante la internación se provee la medicación para la inhibición de la lactancia y se programa, como a todas las mujeres, una consulta en un consultorio del centro obstétrico denominado de "puerperio". Este fue el último contacto con los médicos obstetras de todas las mujeres que conocimos. Para todas ellas, la atención médica posterior al parto estuvo centrada en el proceso diagnóstico de sus bebés. Así, además de los habituales controles neonatológicos primero y pediátricos después, sus hijos fueron atendidos en un consultorio de infectología pediátrica durante un año y medio en donde se les prescribieron diferentes pruebas diagnósticas. Cabe destacar que ninguno de los hijos de las mujeres cuyas narrativas analizo contaba con un diagnóstico positivo confirmado: dos tenían negativos ya determinados y a los dos restantes se les habían realizado las primeras pruebas con resultados negativos pero debían esperar, un año en un caso y ocho meses en otro para el diagnóstico definitivo.

Horizontes Antropológicos, Porto Alegre, ano 15, n. 32, p. 247-272, jul./dez. 2009 
en un centro de atención primaria cercano a su casa. Allí le ordenaron el primer test de Elisa. Si bien le avisaron que le iban a pedir el test no recuerda haberlo consentido: "eso era para hacerse sí o sí, no sé, no era obligatorio pero lo tenían que hacer pero no me hacían firmar nada". A la semana, al volver al centro, le sacaron sangre nuevamente, porque en el primer análisis, según recuerda, "no salió nada". Cuando volvió la semana siguiente a una consulta obstétrica le comunicaron que el test había salido reactivo: "y yo me quedaba en el aire te lo juro, yo no podía creerlo...". A partir de entonces la derivaron al hospital para el seguimiento del embarazo y su atención en infectología. Desde que le comunicaron el diagnóstico Paula realizó numerosos trámites para conseguir finalmente la medicación, trámites engorrosos y complicados que lo fueron aun más dada su nacionalidad. Dice extrañar mucho a su país, su familia y sus afectos, pero se queda en Argentina porque en Paraguay no tendría acceso al tratamiento antirretroviral. A continuación Paula narra su experiencia en el parto:

P: $[\ldots]$ antes de tener a mi bebé estuve internada 3 días [...] porque ellos se equivocaron [risa leve] ¿cómo te digo? todo el tiempo se equivocaban conmigo [...] mis análisis de VIH salieron muy altos pero todavía no estaba con tratamiento, entonces eso le había mostrado en obstetricia acá [...] entonces me atendió [el obstetra de alto riesgo] y dijo que tenía que dejarme internada acá [...] un estudio viejo, esa vez todavía no tenía el resultado del segundo estudio después de la medicación. Esa misma tarde tenía turno con el [infectólogo] y me hizo una nota de que me bajó mucho la carga entonces al día siguiente vine para quedarme internada, creo que ellos no se fijaron tampoco ahí esa vez, por eso me tuvo internada, porque ya me iba a hacer cesárea esa vez, no sabían de la nota del [infectólogo] un día cuando estaba internada ahí, yo tenía todos mis papeles en mi sala, entonces me vino a la cabeza y me fui corriendo para venir a traerme la orden que me dio el [infectólogo] antes, y bueno, justo cuando estaban hablando todos los doctores ahí, a una obstetra le pasé la nota, abrió y ahí empezaron a leer, y ahí se dieron cuenta que hay muy poca posibilidad, entonces tiene que ser por parto normal y ahí entonces empezaron a hablarse entre ellos, que más bueno parto normal, todo eso así $[\ldots]$ bueno, opinaron y dijeron que era mejor, el parto normal, entonces después al día siguiente me mandaron otra vez, me dieron de alta

A: ¿y después cuándo volviste?, ¿pasó mucho tiempo hasta que rompiste bolsa?

P: a ver 15 de marzo me vine a quedarme internada y después 17 de marzo salí otra vez y llegué el 23 de marzo, 23 de marzo me quedé un día, el 24 de marzo recién lo tuve

A: y ahí otra vez casi te mandan al cuchillo nuevamente [ríe]

Horizontes Antropológicos, Porto Alegre, ano 15, n. 32, p. 247-272, jul./dez. 2009 
P: sí, porque yo cada vez que venía traía todo en una carpeta mis papeles tenía un montón y entonces una de esas se le escapó, y estaba abierto el papel y se le escapó. Yo le había dicho cuando me tenía todo con el suero, porque yo sabía que tenía una nota, que tenía muy poca posibilidad de contagiarse, entonces yo le expliqué, “¿y dónde está el papel?” me dice, y está entre mis carpetas, entre los papeles que habían dejado, o sea que como yo antes de entrar tenés que ya hacer todos los trámites y se quedan los papeles [...] creo que ese día iba a ser operada yo, creo que se equivocaron, y después otra vez se dieron cuenta casi me hicieron por cesárea, casi me morí ese día [ríe] porque ese mismo día me iban a hacer la operación de la cesárea, ese mismo día me iban a hacer, porque no había más tiempo, ellos solamente se fijaban en el resultado viejo y en el nuevo no, eso es lo que pasaba

A: claro, y vos me decías que vos preferías parto normal...

P: sí, sí, prefería la verdad que sí... yo tenía al principio tenía más o menos miedo de los dos, por la cesárea que dicen que no se siente cuando te hacen, otro cuando el parto que dicen que se sufre un montón, yo la verdad que te digo no sufrí tanto, superé mi miedo, después cuando estuve ahí ya... ya no pensé en más nada sino lo que voy a hacer, lo que voy a procurar es tener bien a mi bebé, estuvo todo bien, salió bárbaro, bárbaro, no me puedo quejar, no pasé... la verdad te digo no pasé mucho dolor, no sentí nada, para mí fue algo mágico, muy lindo...

En el relato de Paula, su experiencia de atención previa al parto aparece plagada de incomunicaciones y desencuentros entre los distintos profesionales y servicios. Y es ella quien articula las distintas instancias de ese circuito de atención fragmentado en el cual cada profesional se limita a monitorear su "objeto de intervención" específico. Pero, al mismo tiempo, ella es "prescindible": les entrega a los obstetras la nota del infectólogo traspapelada e inmediatamente los médicos, "empezaron a hablarse entre ellos, que más bueno parto normal, todo eso así [...] bueno, opinaron y dijeron que era mejor, el parto normal"'.

De un modo llamativamente similar en el trabajo de Beatriz Cortés (1997, p. 105), Berenice, quien ha sufrido una fractura ósea y cuyas desventuras en el sistema médico analiza la autora, cuenta:

[...] finalmente me hacen pasar donde está él (el Dr. X), detrás de un escritorio; apenas saluda, y se pone a mirar las radiografías mientras los dos médicos le explican; mi impresión es que yo estaba totalmente de más, él hablaba con sus ayudantes y con la radiografía [...]. 
Pero, a diferencia de Berenice, Paula finalmente pudo tener un parto vía vaginal como quería, aunque al precio de haber sufrido una internación innecesaria durante tres días. En ese espacio de racionalidad técnica Paula logró instalar su deseo, que era habilitado por ese papel que certificaba una carga viral inferior a 1000 copias, pero que ella misma se procuró. La posibilidad de cumplir ese deseo se realizó en la medida en que Paula pudo articular las distintas instancias de atención, pudo "juntar", reintegrar, los fragmentos que (des)componían su cuerpo desde la mirada y la acción médicas y finalmente, a pesar del miedo, pudo vivir un momento "mágico" y sin dolor.

V

Los relatos sobre el momento del parto de las mujeres a quienes se les practicó una cesárea hablan de la diversidad de experiencias de parir estando infectadas por el VIH.

Olivia nos cuenta:

O: bueno no te quiero contar porque si vos no tuviste un hijo ¿viste? como que no te quiero asustar [ríe] pero nunca me imaginé que iba a ser una cosa así ¿viste? ¿Te cuento?

A: sí, contame

O: no, porque, bueno, encima estaba, ponele, lleno de hombres y de mujeres ¿viste? pero más de hombres que de mujeres, me hacen sacar toda la ropa y me hacen subir por una escalerita hasta la camilla, desnuda, viste cuando decís 'ay', te querés matar, yo por lo menos me quería matar, por como soy, por ahí otra A: y te da vergüenza

O: y sí, más vale, y me hacen, me dicen 'sentate como un indio' una cosa así, te hace así, yo con la panza tenía una era pura panza, yo con la panza así, te hacen como medio agachar ¿entendés? como la cabeza en la camilla y te entran a poner... la cesárea yo no sabía que era así... te entran a poner inyecciones en la espalda como si fuese en los huesos, a mi por lo menos me re dolió mal, fue lo que más me dolió, después con la anestesia no sentís nada [...]

Los procedimientos a los que deben someterse los pacientes en la institución hospitalaria, constituyen un factor esencial que interviene en el fluir de "persona social" a "procesos patológicos o naturales" que se desenvuelve en la atención biomédica, proceso a través del cual "la medicina crea sus otros

Horizontes Antropológicos, Porto Alegre, ano 15, n. 32, p. 247-272, jul./dez. 2009 
y construye su objeto" (Frankenberg, 1988, p. 17, traducción nuestra). En el relato de Olivia esta conversión en paciente, se hace presente cuando su cuerpo pierde el carácter privado. La desnudez, fría y descarnada, lo hace público, lo despersonaliza y lo prepara para la intervención médica. "Sentate como un indio" es un paso dentro de una rutina preestablecida, formal e impersonal, que no reconoce cuerpos -en sentido de nuestros "cuerpos vividos", claro está- sino "cuerpos objetos" que deben ser sometidos a los procedimientos pautados: "me hacen sacar toda la ropa...", "me hacen subir...", "te hacen medio como agachar...", "te entran a poner inyecciones...". Pero ese cuerpo que es intervenido y dirigido por los pasos rutinizados de la cesárea es al mismo tiempo el cuerpo que le da vergüenza “"ay' te querés matar” y el cuerposujeto que es ella misma, que conforma una unidad con su self: "por como soy, por ahí otra...".

El relato continúa:

A: ah ¿eso será la peridural?

O: claro algo así la anestesia, bueno no sé cuántas, ponele 4, creo que eran, no sé, yo creo que porque como soy yo ¿entendés? porque por ahí otra sí, le dolerá un poco pero no se hace tanto problema

A: claro yo soy así también, soy media...

O: ¿cómo yo? Bueno, pero hay algunas que, ponele, tienen parto normal y también dicen que fue re doloroso, yo no sé lo que es un parto normal pero a mí la cesárea me mató, por ahí la que tuvo un parto normal y tiene la cesárea tampoco le va a gustar la cesárea ni el parto normal ¿viste? y bueno, ponele, había como una luz y todo y yo miraba para arriba y se veía, yo veía como, ponele, el agujero que tenía y la sangre veía rojo ¿entendés? una cosa así mucho no quería mirar veía así y sentía como ¿viste cuando? [hace un sonido] una cosa así hace un ruido como que están escarbando algo, bueno y ahí no se qué sacan a la nena, bueno me la ponen así al lado, la veo como podía, porque estaba... y después me agarró como un ataque de nervios ¿entendés? yo estaba claro así te atan los brazos no sé que sí para que no te muevas ni nada, llegas a moverte o algo y después empezaron a coser $[\ldots]$ y bueno, me había agarrado como un ataque de nervios, empecé como medio a temblar así me pareció como que se asustaron ¿entendés? 'no, ¿qué le pasa?' una cosa así

A: ¿los nervios porque te dio mucha impresión?

O: no sé, porque se ve que después me agarró como un tembleque, no sé por qué, yo dije 'yo me voy de acá' ¿viste? una cosa así, no sé por qué es eso [...]

Horizontes Antropológicos, Porto Alegre, ano 15, n. 32, p. 247-272, jul./dez. 2009 
En The woman in the body, Emily Martin (1987, p. 82, traducción nuestra) planteó que el uso de anestesia epidural y, especialmente, la realización de una cesárea "afecta(n) a las mujeres de un modo diferente y a menudo más negativo que el parto vaginal", de modo que se experimenta un sentimiento más fuerte de "estar fuera de control, afín pero más extremo que la intensa experiencia de fragmentación que las mujeres experimentan en el parto vaginal". Tal como lo relatan las mujeres en los extractos de entrevistas seleccionados en el libro de Martin, esta vivencia se expresa en un sentimiento explícito de fragmentación del propio cuerpo y el self ya que los médicos intervienen sobre el cuerpo de la mujer, que es un objeto que manipulan, pero sin prestarle atención a ella. La autora desarrolla extensamente su visión sobre la analogía del nacimiento con la producción de mercancías y plantea que el sentimiento de alienación respecto del propio cuerpo es comparable al del trabajador alienado de su producto de trabajo en el sistema capitalista. Y que

[...] aunque las mujeres resisten procedimientos médicos específicos como la cesárea o la anestesia durante el parto, ellas no parecen poder resistir el supuesto subyacente a estos procedimientos: que el self y el cuerpo están separados, que las contracciones son involuntarias, que el nacimiento es producción [...]. (Martin, 1987, p. 89, traducción nuestra).

En algunos fragmentos de la narración de Olivia el cuerpo, su cuerpo, se presenta en efecto separado de ella misma: "ve" su vientre abierto a través de un reflejo en la luz del techo, "ve" sangre, "escucha" ruidos; incluso, en algunos pasajes del relato, pareciera que habla de un cuerpo que no es el de ella, un cuerpo ajeno. En este sentido la perspectiva propuesta por Martin permite anclar este sentimiento de separación con respecto a su cuerpo en las modalidades de intervención de la atención obstétrica en el parto. Sin embargo, este aporte, si bien posibilita responder a algunos de nuestros interrogantes iniciales en relación con la experiencia de la fragmentación, deja abierta la pregunta y arroja incertidumbre sobre la posibilidad misma de la (re)integración. Retomaremos más adelante esta cuestión, por el momento me permito dejarla en suspenso para presentar a Elena.

Un viernes por la mañana que estábamos realizando observaciones en la sala (más bien "pasillo") de espera del servicio de infectología, uno de los médicos, justamente quien se había mostrado más reacio a presentarnos

Horizontes Antropológicos, Porto Alegre, ano 15, n. 32, p. 247-272, jul./dez. 2009 
pacientes ${ }^{14}$ nos contactó con una mujer de 26 años que había tenido un bebé en el centro obstétrico un mes y medio atrás, se llamaba Elena. Elena nació y vivió en Cochabamba, Bolivia, hasta que diez meses atrás decidió migrar hacia la Argentina con su hijo de seis años que "crió sola" porque el papá "los abandonó". Antes de venir, estudió un año en la universidad en la carrera de derecho, pero tuvo que dejarla porque "no tenía recursos". Al llegar a Buenos Aires empezó a trabajar como "ayudanta" en un taller de costura, al poco tiempo sospechó estar embarazada y lo confirmó con un análisis de sangre que se realizó en una maternidad de la ciudad. Trabajó hasta los siete meses de embarazo, luego, nos cuenta, le dijeron "no puedes trabajar con un bebé" y se quedó sin trabajo desde entonces. Tres de sus hermanos viven en Buenos Aires con sus compañeras e hijos y la ayudan y apoyan. Su pareja se quedó en Bolivia terminando una licenciatura en derecho y se comunica telefónicamente con él, aunque hacía varios meses que le decía que iba a venir aún no lo había hecho. Al confirmar el embarazo, a los dos meses de gestación, Elena comenzó a atenderse en un centro de atención primaria cercano a su casa en la villa 20 de Villa Lugano; es allí donde le realizaron el primer test de VIH. El relato entre el primer test y la confirmación del resultado reactivo es confuso. Mientras se realizaba los controles prenatales se mudó y perdió contacto con el centro de salud hasta que volvió a atenderse, en el octavo mes de gestación. En ese momento le dijeron que la habían estado buscando para entregarle el resultado definitivo del test que era reactivo y le dijeron que debía dirigirse al hospital con una nota -que era una orden de internación. Elena nos cuenta:

E: [...] entonces me vine acá me hicieron los resultados yo después debía entrar en internación, me internaron, ese mismo día me internaron acá en el hospital, me internaron, estaba de ocho meses, me internaron, estaban esperando todavía que el bebé, se forme bien los pulmocitos, me estaba medicando, me estaba inyectando me sacaban uy sangre ay no yo lloraba

A: ¿te contaban te explicaban qué hacían cuando?

${ }^{14}$ Los médicos infectólogos nos solicitaron emplear la siguiente modalidad para contactar pacientes en el servicio: nosotras aguardábamos en el pasillo del consultorio mientras los médicos atendían, en el curso de la consulta ellos le comentaban que había un grupo de antropólogos (varias veces escuché 'sociólogos') que estaban haciendo una investigación en el hospital y les preguntaban si estaban dispuestos a conceder una entrevista; cuando la persona accedía nos la presentaba en el pasillo y acordábamos el encuentro.

Horizontes Antropológicos, Porto Alegre, ano 15, n. 32, p. 247-272, jul./dez. 2009 
E: no, no, no me decían nada, sólo me sacaban la sangre, y me decían 'esto es para que sepas cuánto de virus tienes qué cantidad' sólo eso luego me sacaban análisis, me sacaba el doctor, así nomás y le decía 'qué qué salió' 'es la orden del doctor tienes que sacarte sangre', 'bueno está bien' [ríe] yo decía resignada como sabía, una experiencia así, yo me ponía a llorar a veces ahí, contaba los días parecía una eternidad decía quiero salir

A: ¿cuánto tiempo estuviste internada?

E: casi dos semanas yo quiero salir porque día y noche no se podía, estaba... ya más pensaba bueno mi otro nene cómo qué está haciendo

A: ¿con quién se quedó el nene?

E: con mi hermano, yo no sabía, venían a visitarme me dijo 'mami por qué no estás conmigo' lo sentí re-deprimido me dijo 'cuándo va a salir el bebé de la panza' me decía 'no' ah me puse a llorar enseguida yo le decía al doctor 'me quiero ir, me quiero ir' [...] como tenía que ser cesárea, me alistaron para... con todos bien envueltos bien protegidos, me dicen 'sí ¿tienes VIH?', 'sí' le digo, me envolvieron como no sé qué, después me inyectaron, estaba ahí, sentía lo que le sacaban al bebé pero de rato yo le decía ‘¿ya terminó?’ decía porque sentía que me sacaban algo de la panza, así que me succionaban la sangre no sé, no lo escuchaba llorar al bebé, porque para mí que lo sacaron con la bolsa y se lo llevaron a otro lado y después que yo salí de cirugía después de dos horas después me lo trajeron...sí y por ahí yo estaba yo estaba como tres horas ahí [...] me llevaron a mi cama donde yo estaba [...] ya compartiendo con otras señoras así embarazadas me decían 'habla ¿qué tienes?' me decían más antes yo estaba internada, yo lloraba porque no podía estar conmigo el pensamiento de qué, qué voy a hacer más adelante, por qué me ha pasado esto[...]

En el relato de Elena sobre la internación ${ }^{15}$ y la cesárea, su cuerpo se presenta como un objeto pasivo sobre el cual se efectúan los distintos procedimientos para evitar la trasmisión madre-hijo: "me estaba medicando, me estaba inyectando me sacaban, uy, sangre...". Ella desconoce y no tiene control sobre lo que se le realiza y la internación, además, refuerza este sentido de desposesión del propio cuerpo. Sólo le queda resignarse -como dice- y llorar...

\footnotetext{
15 A lo largo de la etnografía pudimos relevar la existencia de una modalidad de internación denominada "por causas sociales", en la cual los y las profesionales "evalúan" el cuidado del embarazo llevado a cabo por la mujer. Así mujeres que, a juicio del personal de salud, no cumplieran con el tratamiento médico indicado o que no tuvieran suficientes controles prenatales, debían ser internadas en la maternidad para asegurar el cumplimiento de los cuidados indicados.
}

Horizontes Antropológicos, Porto Alegre, ano 15, n. 32, p. 247-272, jul./dez. 2009 
Volvamos a Olivia y el final de su relato: “[...] me había agarrado como un ataque de nervios, empecé como medio a temblar así me pareció como que se asustaron ¿entendés? no ¿qué le pasa? una cosa así [...] me agarró como un tembleque, no sé por qué, yo dije 'yo me voy de acá' [...]". En el contexto de la narración de su cesárea, el temblor, involuntario, está unido a su "estado de ánimo" (mood) (Rabelo; Souza, 2003), que difícilmente puede ser explicado (como cuando se lo pregunto directamente en la entrevista) porque es fundamentalmente un sentido vivido, aunque al final lo liga a "yo dije, yo me voy de acá". El "tembleque" no expresa un control directo sobre su cuerpo, ya que no puede controlarlo, pero es parte del sentir de un cuerpo que parece no pertenecerle, que parece fragmentado y escindido pero que sin embargo le pertenece y la constituye. Es la manera en que Olivia, como un cuerpo-sujeto, aparece en el quirófano, ante la mirada atónita de los médicos que, como cuenta, "se asustaron".

En el caso de Elena, dada la internación forzada para realizar el tratamiento de profilaxis y la modalidad en que se le practicó la cesárea, el llanto es la única manera en que ella se hace presente. Incluso si prestamos atención a la manera en la que ella se expresa, el "yo" que narra sólo se presenta activo en el "yo lloraba", "yo me ponía a llorar", "(yo) me puse a llorar".

Los "estados de ánimo" (moods) están enraizados en nuestros cuerpos, son el sentido corporificado (embodied) de nuestro lugar en un contexto dado que refiere a un modo determinado de involucramiento con los otros y en el mundo. Las emociones, así, no están "en” el interior de los cuerpos sino en las acciones que desplegamos en el mundo, son sociales y respaldadas por procesos grupales, de algún modo son irreductibles al organismo y al individuo particular que las siente (Williams; Bendelow, 1996). En este sentido, los estados de ánimo no son estados internos que obtienen expresión en la experiencia, ni son reacciones a estímulos externos, sino que se constituyen y articulan en un contexto relacional en el cual estamos involucrados y el cual ya tiene un tono afectivo (Rabelo; Souza, 2003).

A través del llanto, Elena está implicada en la situación y en la relación con los otros, a partir de sus sentimientos y de su historia. El llanto la involucra en el proceso de recibir el diagnóstico, el desagrado por una internación que no entiende, el deseo de volver a su casa, la preocupación y la angustia por su hijo más grande que debe quedarse con su tío. Revela de alguna manera el modo en que está absorbida por y en el mundo y revela también el modo en 
que experimenta en y desde su cuerpo el recibir el diagnóstico de infección por VIH estando embarazada y el tener que disponer su cuerpo para el tratamiento de profilaxis de trasmisión vertical.

VI

Como lo plantea Martin, las mujeres encuentran, en el marco de la atención obstétrica, modos para resistir prácticas médicas a menudo desagradables $\mathrm{y}$ violentas que suponen una visión fragmentaria de sus cuerpos. Asimismo hemos encontrado que en oportunidades también las aceptan y justifican, colaborando en el cuidado del "producto" final.

Hemos visto además que en el curso de la experiencia de embarazarse y recibir un diagnóstico de infección por VIH durante los controles prenatales, el cuerpo, a través de su fragilidad, adquiere una nueva visibilidad e interroga a las mujeres sobre sus historias y su futuro posible, poniendo en tensión la integridad de la imagen que ellas tienen de sí. La organización y realización de la atención obstétrica e infectológica, refuerza esta desintegración al concentrarse en la prevención de la trasmisión vertical del VIH y el desarrollo del embarazo, sin ofrecer un espacio donde las mujeres puedan canalizar sus preocupaciones referidas a su propio cuerpo, su propia salud (recordemos la fuerte asociación sida-muerte que manifestaba Vanina) y su propio futuro. Así, a partir de su forma de intervención, que disocia la enfermedad y el sujeto, la medicina profundiza la fragmentación cuerpo-self y fracasa en funcionar como un otro, como un punto de apoyo a partir del cual el sujeto se reubique frente a y con su padecimiento (Cortés, 1997).

Sin embargo, el análisis de las narrativas de estas mujeres, pone de relieve que la fragmentación que experimentan con sus cuerpos, antes que ser una representación consciente, es vivida y sentida. Así, la integración de self y cuerpo no requeriría necesariamente una formulación explícita y consciente, sino que, antes bien, se desplegaría, se desenvolvería, realizaría, en el curso mismo de la experiencia de la atención obstétrica. Al considerar el carácter relacional e interactivo de las emociones y los "estados de ánimo", éstos nos ofrecen una vía de acceso posible para analizar los modos en que esa (re)integración es posible, esto es, los modos en que se expresa en el curso mismo de la atención médica lo que Csordas (1994) llama "agencia corporificada" (embodied agency). 
En los relatos de Vanina, Paula, Olivia y Elena pudimos ver que en el curso de la atención obstétrica experimentan un continuo proceso de fragmentación y (re)integración, sin que este último corresponda necesariamente al plano de la enunciación racional. Así es en el mismo transcurrir de la experiencia en la atención médica en donde se despliegan los modos posibles de integración, que se expresan de maneras diversas en función de las diferentes trayectorias y biografías.

Frankenberg (1988) ha señalado que la "performance biomédica de la curación" no se ocupa ni de personas sociales, ni de procesos fisiológicos o patológicos exclusivamente, sino más bien de las transiciones entre ambos órdenes. Así, lo que debe ser controlado son los movimientos entre el cuerpo-objeto que se construye en el hospital y el embodied patient (el paciente corporificado). ${ }^{16} \mathrm{El}$ tránsito entre uno y otro es fundamentalmente negociado y no el producto del control unilateral ejercido por la medicina, pero en él el paciente negocia desde una posición de desigualdad, disrupción e incertidumbre.

Las mujeres que conocimos realizando nuestra etnografía pudieron negociar de un modo variable (y no explícito, ni necesariamente reflexivo) este fluir de persona a paciente, o de cuerpo-sujeto a cuerpo-objeto médico, que se desenvuelve continuamente en la atención. Este proceso fue modelado por la trayectoria terapéutica de la mujer, sus encuentros y desencuentros con el sistema de salud, su propia historia y, fundamentalmente, el cumplimiento del objetivo principal (tanto de la mujer como del personal de salud) de evitar la trasmisión del VIH a su hijo. Así, el orden y los objetivos impuestos por la atención médica condicionan los modos en que puede realizarse la (re)integración. Paula pudo negociar su "momento mágico", entre otras cuestiones, porque había recibido el diagnóstico tempranamente, había tomado medicación y tenía un análisis de carga viral inferior a las 1000 copias. Elena recibió tarde la confirmación del diagnóstico y debió internarse por varias semanas para que se asegurara el cumplimiento del tratamiento antirretroviral y los controles necesarios, sólo le quedó resignarse y llorar. Pero aun en el llanto y en la resignación se hace presente como un cuerpo que vive, que siente, que

16 Este movimiento entre cuerpo-objeto y cuerpo-sujeto remiten a la "trágica e inevitable" contradicción de la llamada "medicina científica" señalada por el mismo autor (Frankenberg, 1988, p. 10-11): mientras que su aplicación se efectúa sobre la disease (esto es, la perturbación de las funciones corporales vista en términos de una entidad biológica), su práctica y eficacia, "el arte de curar" requieren de la persona que padece (illness).

Horizontes Antropológicos, Porto Alegre, ano 15, n. 32, p. 247-272, jul./dez. 2009 
sufre, que tiene una historia y que se pregunta por el futuro. Es la manera en que pudo lograr ese tránsito de proceso patológico a persona social.

\section{Referencias}

ALVES, P.; RABELO, M.; SOUZA, I. Introdução. In: ALVES, P.; RABELO, M.; SOUZA, I. (Ed.). Experiência da doença e narrativa. Rio de Janeiro: Editora Fiocruz, 1999. p. 11-39.

BARBER, N.; MARGULIES, S. Procesos de atención de personas que viven con Vih. Un enfoque desde las trayectorias terapéuticas. In: GRIMBERG, M. (Ed.) Narrativas y experiencias de padecimiento: abordajes antropológicos. Buenos Aires: FFyL-UBA: Santiago Alvarez Editor. En prensa.

COORDINACIÓN SIDA. Situación epidemiológica del VIH-Sida en la ciudad de Buenos Aires. Infosida, Buenos Aires: Gobierno de la Ciudad de Bs.As., n. 5, p. 4-26, marzo 2006.

CORTÉS, B. Experiencia de enfermedad y narración: el malentendido de la cura. Nueva Antropología, México, v. 16, n. 52, p. 89-115, agosto 1997.

CSORDAS, T. J. Introduction: the body as representation and being-in-the-world. In: CSORDAS, T. J. (Ed.). Embodiment and experience: the existential ground of culture and self. Cambridge: Cambridge University Press, 1994. p. 1-24.

FRANKENBERG, R. 'Your time or mine': temporal contradictions of biomedical practice. In: FRANKENBERG, R. (Ed.). Time, health and medicine. Uxbridge: Brunel University, 1988. p. 1-30.

GAGLIOLO, G. 'Porque somos, viste, la pata social'. Un análisis del papel del servicio social en la atención de personas que viven con VIH. In: CONGRESO ARGENTINO DE ANTROPOLOGÍA SOCIAL, 8., 2006, Salta. Anales... Salta: Universidad Nacional de Salta, 2006. 1 CD-ROM.

GARCÍA, G. La prevención de la trasmisión vertical del VIH-Sida: etnografía de un centro obstétrico de un hospital de agudos del sur de la ciudad de Buenos Aires. Tesis (Licenciatura en Ciencias Antropológicas)-Facultad de Filosofía y Letras, Universidad de Buenos Aires, Buenos Aires, 2007a. 
GARCÍA, G. La prevención de la trasmisión vertical y la atención obstétrica de mujeres viviendo con VIH: un estudio antropológico. In: REUNIÃO DE ANTROPOLOGIA DO MERCOSUL, 7., VII, 2007, Porto Alegre. Anais... Porto Alegre: ABA: UFRGS, 2007. 1 CD-ROM.

GARRO, L.; MATTINGLY, C. Narrative as construct and construction. In: GARRO, L.; MATTINGLY, C. (Ed.). Narrative and the cultural construction of illness and healing. Los Angeles: University of California Press, 2000. p. 1-49.

GOOD, B. Medicine, rationality, and experience: an anthropological perspective. Cambridge: Cambridge University Press, 1994.

GOOD, B.; DEL VECCHIO GOOD, M. J. "Fiction" and "historicity" in doctors' stories: social and narrative dimensions of learning medicine. In: GARRO, L.; MATTINGLY, C. (Ed.). Narrative and the cultural construction of illness and healing. Los Angeles: University of California Press, 2000. p. 50-69.

GRIMBERG, M. Narrativas del cuerpo. Experiencia cotidiana y género en personas que viven con VIH. Cuadernos de Antropología Social, Buenos Aires, n. 17, p. 79-99, agosto 2003.

KIRMAYER, L. The body's insistence on meaning: metaphor as presentation and representation in illness experience. Medical Anthropology Quarterly, v. 6, n. 4, p. 323-346, 1992.

MARTIN, E. The woman in the body: a cultural analysis of reproduction. Boston: Beacon, 1987.

MENÉNDEZ, E. L. Sistemas locales de salud: aproximaciones teóricometodológicas. México: CIESAS, 1990. Mimeo.

MENÉNDEZ, E. L. Las furias y las penas: o de cómo fue y podría ser la antropología. Conferencia Inaugural $50^{\circ}$ Aniversario de la Carrera de Ciencias Antropológicas en la Universidad de Buenos Aires. Buenos Aires: Editorial de la Facultad de Filosofía y Letras, Universidad de Buenos Aires, abr. 2008.

MERLEAU-PONTY, Maurice. Fenomenología de la percepción. Buenos Aires: Planeta Agostini, 1993. 
MINISTERIO DE SALUD. Programa Nacional de Lucha contra los Retrovirus del Humano, VIH-Sida y ETS. Boletín sobre el VIH-Sida en la Argentina, año 11, n. 26, Buenos Aires, agosto 2008.

OCHS, E.; CAPPS, L. Narrating the self. Annual Review of Anthropology, v. 25, p. 19-43, 1996.

RABELO, Miriam. Narrando a doença mental no Nordeste de Amaralina: relatos como realizações práticas. In: ALVES, P.; RABELO, M.; SOUZA, I. (Ed.). Experiência da doença e narrativa. Rio de Janeiro: Editora Fiocruz, 1999. p. 75-88.

RABELO, M.; SOUZA, I. Temporality and experience: on the meaning of nervoso in the trayectory of urbarn working-class in Northest Brazil. Ethnography, v. 4, n. 3, p. 333-361, 2003.

RECODER, M. L. Vivir con VIH. Notas Etnográficas sobre el mundo de la enfermedad y sus cuidados. Tesis (Doctorado en Ciências Sociais)-Faculdade de Filosofia e Ciências Humanas, Universidade Federal da Bahia, Salvador, 2006.

RICOEUR, P. Tiempo y narración: la triple mimesis. In: RICOEUR, P. Tiempo y narración I: configuración del tiempo en el relato histórico. México: Siglo XXI, 1995. p. 113-168.

WILLIAMS, S. The vicissitudes of embodiment across chronic illness trajectories. Body and Society, v. 2, n. 2, 1996. p. 23-47.

WILLIAMS, S.; BENDELOW, G. The emotional body. Body and Society, v. 2, n. 3, 1996. p. 125-139. 